\title{
Crack Propagation Under Constant Amplitude Loading Based on an Energetic Parameters and Fractographic Analysis
}

\author{
Mohamed Benguediab*, Benattou Bouchouicha, Zemri Mokhtar, Mohamed Mazari \\ Laboratory and Reactive Systems, Department of Mechanical Engineering, \\ University of Sidi Bel Abbes, Algeria
}

Received: March 8, 2012; Revised: April 16, 2012

\begin{abstract}
The crack propagation behavior in a 2024 T351 Aluminum Alloy under constant amplitude loading has been studied. This study is complemented by quantitative microfractographic observations and energetic analysis. The obtained results under constant amplitude fatigue tests show that different crack propagation stages can be identified and correlated with the evolution of the characteristic features. In another hand, the energetic analysis shows that there is a discontinuous crack growth at low growth rates as against a cycle by cycle growth mechanism at high growth rates.
\end{abstract}

Keywords: fatigue crack growth, energy dissipated, features, dimples, striations

\section{Introduction}

Fatigue crack growth resistance of a material depends upon a number of factors, such as its composition, mechanical properties and heat treatment conditions, external loading and the ambient environment.

Understanding of the mechanisms governing fatigue crack has made significant advances since the Paris law proposed about 40 years ago ${ }^{1}$.

This relationship can show several stages separated by transitions (Figure 1) 2-4 $^{2}$ Predominant micro structural size, the ambient environment and the frequency of solicitation can modify the behavior of the crack growth curves $(\mathrm{da} / \mathrm{dN}$ vs $\Delta \mathrm{K})$ and the transitions ${ }^{3}$.

There exists a threshold of non propagation under which a preexistent long crack does not grow ${ }^{5}$. The value of $\Delta \mathrm{K}_{\mathrm{th}}$ is a function of the load ratio $\mathrm{R}$ and the environment ${ }^{3,5}$.

For medium crack growth rates $\left(\left(10^{-8}<\mathrm{da} / \mathrm{dN}<10^{-5}\right)\right.$ $\mathrm{m} /$ cycle for aluminum alloys), the relationship between $\mathrm{da} / \mathrm{dN}$ and $\Delta \mathrm{K}$ is characterized by independent constant slope of the load ratio $\mathrm{R}$.

This stage is also characterized by the existence of fatigue striations whose interval can be directly correlated with macroscopic crack growth rate ${ }^{6-8}$. In this stage, the crack growth behavior is characterized in considering the effect of crack closure effect ${ }^{9}$.

For crack growth rates greater than $10^{-6} \mathrm{~m} /$ cycle, we notice an increasing in the crack growth rate as we approach the static rupture conditions ${ }^{10}$.

In Ranganathan work, an energetic approach ${ }^{11,12}$ based on the theoretical model of Weertman ${ }^{12}$ permits a better comprehension of mechanisms of propagation with a possible correlation between macroscopic and microscopic mechanisms.

This paper presents the results of a quantitative analysis of the characterized features with respect to different

*e-mail: benguediab_m@yahoo.fr parameters governing the crack propagation behavior completed by an energy analysis.

\section{Experimental Details}

The study was conducted on the high strength aluminum alloy 2024 T351. Nominal composition and mechanical properties are given in Table 1 and 2.

The tests are conducted on compact tension specimens $12 \mathrm{~mm}$ thick and $75 \mathrm{~mm}$ wide, with the crack growth in the LT orientation.

The constant amplitude tests at five $\mathrm{R}$ ratios $(0,01 ; 0,10$; 0,$33 ; 0,54$ and 0,70 ) were carried out initially to characterize the material behavior.

All the tests were carried out under computer control at $20 \mathrm{~Hz}$ in ambient air and at selected crack length, the evolution of the crack mouth opening displacement $\delta$ (measured by a clip gage) and the differential displacement $\delta$ ' with respect to the load $\mathrm{P}$ were recorded on a XY plotter at a frequency of $0,2 \mathrm{~Hz}$. $\delta$ ' is defined by (Equation 1):

$\delta^{\prime}=\delta-\alpha P$

Where $\alpha$ is the specimen compliance at a particular crack length. The measurements were carried out during one cycle for constant amplitude tests and during one block for a reduced spectrum loading.

Typical $\delta$ vs $\mathrm{P}$ and $\delta$ ' vs $\mathrm{P}$ diagrams for constant amplitude loading are given in Figure 2.

Crack opening load Pop was measured at the beginning of the horizontal portion on $\delta$ ' vs $\mathrm{P}$ diagram $^{13}$.

The Hysteresis energy per cycle, Q, was measured numerically integrating the area under the load versus amplified displacement diagrams measured under the loading line of the specimen. The specific energy $U_{S}$ is defined as (Equation 2): 


$$
U_{S}=\frac{Q}{2 B \times \frac{d a}{d N}}
$$

Where "B" is the thickness of specimen and "da/dN" the crack growth rate.

After the tests, the broken surfaces were examined under scanning microscope, at different magnifications varying from 200 to 10000 to identify and quantify different fractographic features. A method for quantitative analysis of fatigue fracture surfaces is proposed, the following technique method presented in ${ }^{14,15}$ is used.

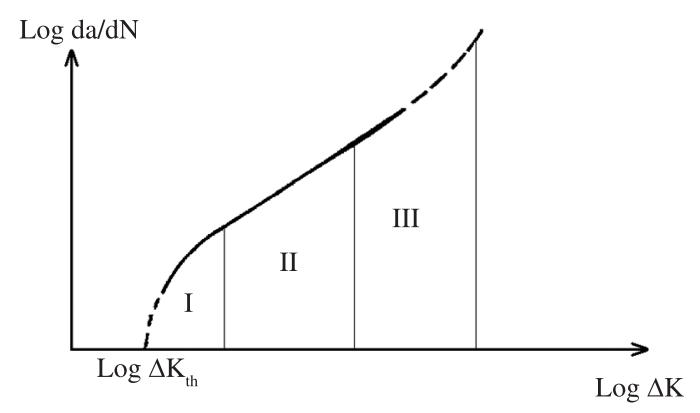

Figure 1. Typical evolution of $\log$ da/dN vs $\log \Delta \mathrm{K}$.

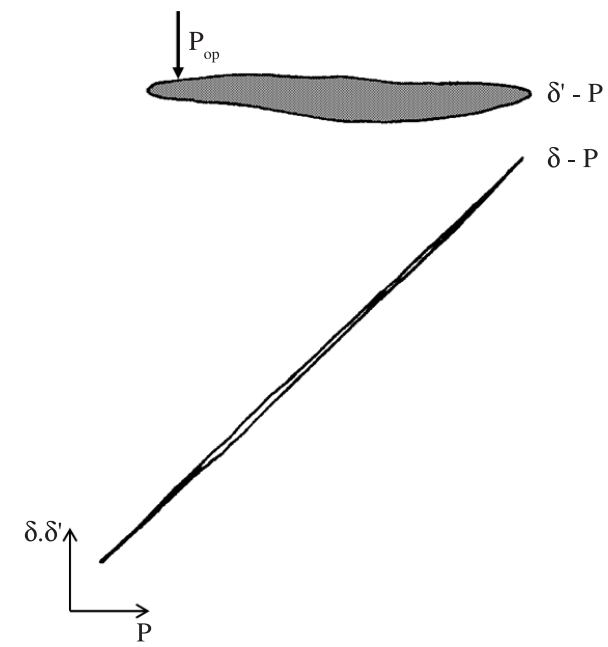

Figure 2. Measurement of the crack opening displacement $\delta$ and differential displacement $\delta$ ' with respect the load P.

Table 1. Nominal composition of the aluminum alloy $2024 \mathrm{~T} 351$.

\begin{tabular}{cccccccccc}
\hline Element & $\mathbf{S i}$ & $\mathbf{F e}$ & $\mathbf{C u}$ & $\mathbf{M n}$ & $\mathbf{M g}$ & $\mathbf{C r}$ & $\mathbf{Z n}$ & $\mathbf{T i}$ & $\mathbf{A l}$ \\
\hline Mean $\%$ & 0.1 & 0.22 & 4.45 & 0.66 & 1.5 & 0.01 & 0.04 & 0.02 & rest \\
\hline
\end{tabular}

Table 2. Mechanical properties of the aluminum alloy 2024 T 351.

\begin{tabular}{lc}
\hline Monotonic yield stress (MPa) & 302 \\
Elongation (\%) & 10.1 \\
Strength coefficient, K, (MPa) & 343 \\
Hardening coefficient, n & 0.06 \\
Ultimate tensile strength (MPa) & 474 \\
Cyclic yield stress (MPa) & 500 \\
Cyclic strength coefficient, K', (MPa) & 8811.4 \\
Cyclic hardening coefficient, n' & 0.078 \\
\hline
\end{tabular}

In the present study the relative amount on the main fractographic feature are:

- Pseudo-cleavage ${ }^{16}$ or " fish-bone structure » which is encountered at low $\mathrm{K}$ values this structure differs from the cleavage by the facet that crack path differs slightly from the defined crystallographic planes (Figure 3a).

- Striations 1 (S1), which are classical ductile striations ${ }^{17}$ which can be correlated to the macroscopic crack growth rate (Figure $3 b$ ).

- Striations 2 (S2), they are more pronounced markings than striations 1 and the spacing between these striations seem to be independent of the macroscopic crack growth rate(Figure $3 b$ )

- Dimples 1 (D1) which represent decohesions observed at low $\mathrm{K}$ values (Figure 3b)

- Dimples 2 (D2) which are classical dimples observed at relatively high $\mathrm{K}$ values.

\section{Experimental Results}

The evolution of da/dN with respect to $K_{\max }$ and $\Delta K$ for five different $\mathrm{R}$ ratios is given in Figures $4 \mathrm{a}$ and $4 \mathrm{~b}$. The stress intensity factor $\Delta \mathrm{K}$ and $\mathrm{K}_{\max }$ are determined according to ASTM standards ${ }^{18}$.

The results are comparable to those obtained by Wanhill ${ }^{3}$ for the same material. The rates obtained at $\mathrm{R}=0.01$ and $\mathrm{R}=0.1$ are similar. We noted that on the Figure $4 \mathrm{a}$ and $4 \mathrm{~b}$, the existence of transitions $\left(\mathrm{T}_{1}, \mathrm{~T}_{2}, \mathrm{~T}_{3}\right)$ characterized by a change of on the curves when the relation da/dN vs $\Delta \mathrm{K}$ is different. The different transitions observed are identified in Table 3.

The analysis of these results proves the existence of four domains of cracks $^{19}$.

\subsection{Results of quantitative fractographic analysis}

In a first approach, only two classes of features were considered: a first one including the pseudo-cleavage areas and striations and a second on including D1 and D2 dimples.

Typical results are given in Figure 5. It can notice at low $\mathrm{K}_{\max }$ values almost the entire surfaces is occupied by pseudo-cleavage facets. At $\mathrm{K}_{\max }$ values corresponding

Table 3. Transitions in crack growth behavior $\left(\mathrm{da} / \mathrm{dN}^{-1}: \mathrm{m} / \mathrm{cycle}^{-1}\right.$, $\left.\Delta \mathrm{K}_{\text {and }} \mathrm{K}_{\text {max }}: \mathrm{MPa} \sqrt{m}\right)$.

\begin{tabular}{|c|c|c|c|c|c|c|}
\hline & $\mathbf{R}$ & 0.01 & 0.10 & 0.33 & 0.54 & 0.70 \\
\hline $\mathrm{T}_{1}$ & $\begin{array}{l}\Delta \mathrm{K} \\
\mathrm{K}_{\max } \\
\mathrm{da} / \\
\mathrm{dN}\end{array}$ & $\begin{array}{c}8.5 \\
8 \\
10^{-8}\end{array}$ & $\begin{array}{c}7.5 \\
8.5 \\
10^{-8}\end{array}$ & $\begin{array}{c}6 \\
9 \\
810^{-9}\end{array}$ & $\begin{array}{c}6 \\
12 \\
7.510^{-9}\end{array}$ & $\begin{array}{c}5 \\
15 \\
810^{-9}\end{array}$ \\
\hline $\mathrm{T}_{2}$ & $\begin{array}{l}\Delta \mathrm{K} \\
\mathrm{K}_{\max } \\
\mathrm{da} / \\
\mathrm{dN}\end{array}$ & $\begin{array}{c}12 \\
12 \\
1.30 \\
10^{-7}\end{array}$ & $\begin{array}{c}11 \\
12 \\
1.3010^{-7}\end{array}$ & $\begin{array}{c}9 \\
12 \\
1.70 \\
10^{-7}\end{array}$ & $\begin{array}{c}7 \\
15 \\
7.210^{-8}\end{array}$ & $\begin{array}{l}- \\
- \\
-\end{array}$ \\
\hline $\mathrm{T}_{3}$ & $\begin{array}{c}\Delta \mathrm{K} \\
\mathrm{K}_{\max } \\
\mathrm{da} / \\
\mathrm{dN}\end{array}$ & $\begin{array}{c}30 \\
30 \\
310^{-6}\end{array}$ & $\begin{array}{c}24 \\
35 \\
310^{-6}\end{array}$ & $\begin{array}{c}21 \\
31 \\
1.60 \\
10^{-7}\end{array}$ & $\begin{array}{c}13 \\
- \\
710^{-7}\end{array}$ & $\begin{array}{c}12 \\
37 \\
410^{-7}\end{array}$ \\
\hline
\end{tabular}




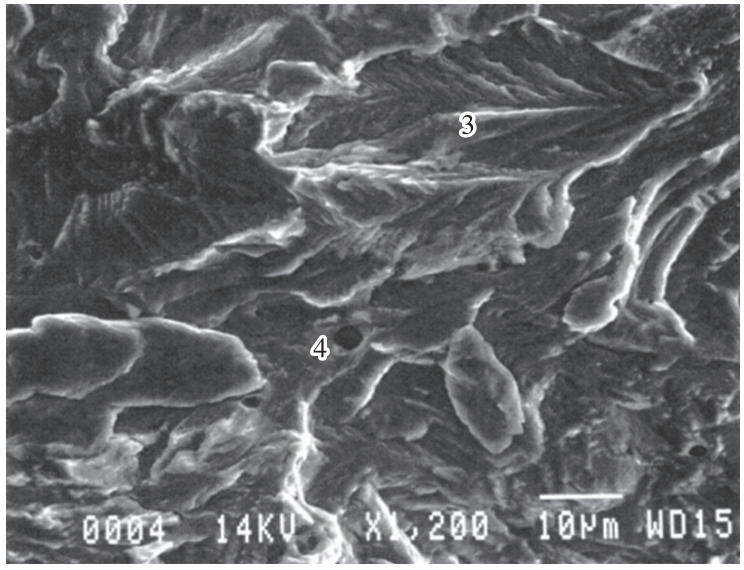

(a)

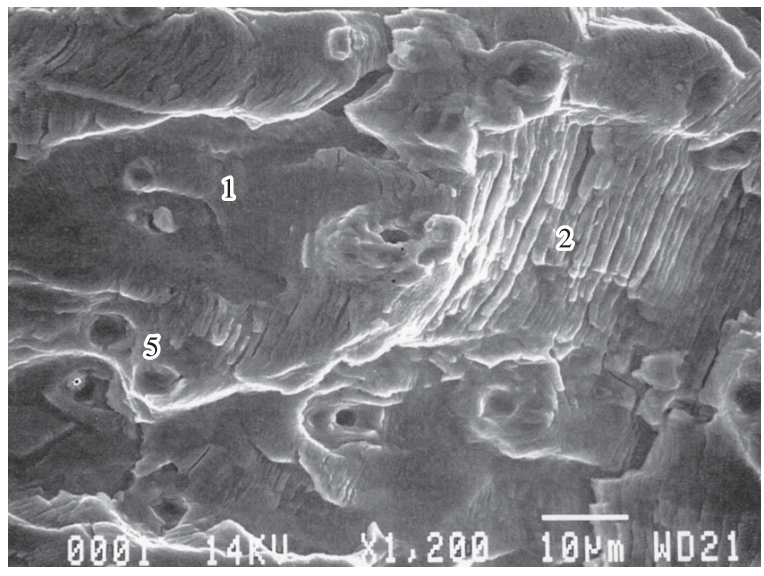

(b)

Figure 3. Different significant fractographic features: (1) Ductile Striations S1, (2) Fragile Striations S2, (3) Pseudo-cleavage (HB), (4) Dimples D1, (5) Dimples D2.

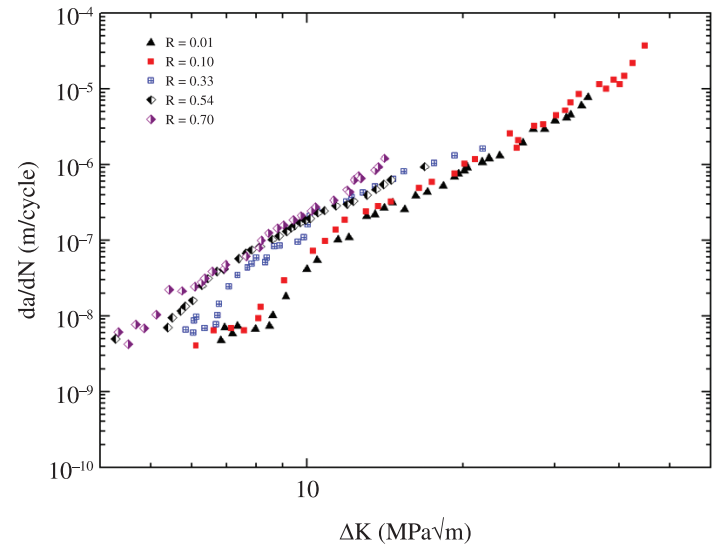

(a)

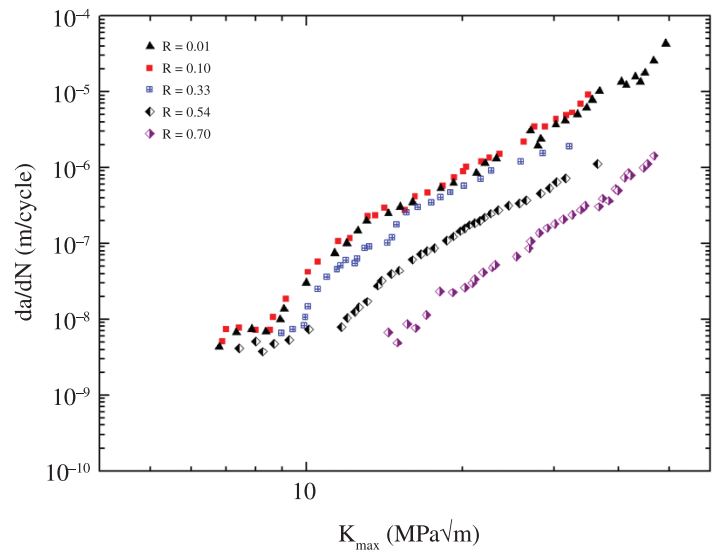

(b)

Figure 4. a) Evolution of the crack growth rate da/dN with respect to the amplitude stress intensity factor $\Delta \mathrm{K}$; b) Evolution of the crack growth rate $\mathrm{da} / \mathrm{dN}$ with respect to stress intensity factor $\mathrm{K}_{\max }$.

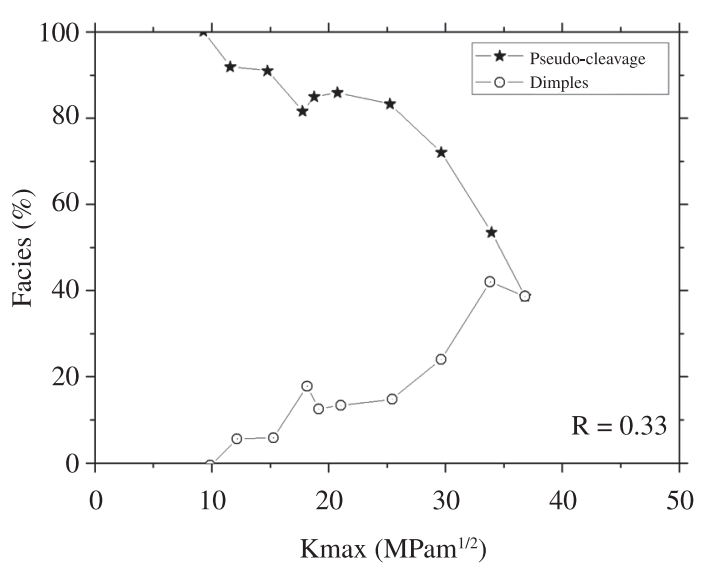

Figure 5. A typical example for evolution of pseudo-cleavage features at $\mathrm{R}=0.33$.

to $\mathrm{T}_{1}$ transition, dimples appear and their relative percentage increase with $\mathrm{K}_{\max }$ until reaching a maximum.

With further increasing $\mathrm{K}_{\max }$ values this percentage decreases before increasing abruptly close the final rupture.
This evolution of dimple percentage suggests that $\mathrm{D}_{1}$ and $\mathrm{D}_{2}$ result from two different mechanisms. This final increase of this percentage can be correlated with the $T_{3}$ transition in the crack growth curves.

To get more precise information a second approach for the quantitative analysis of the fracture surfaces were developed considering three different fractures striations, dimples $\mathrm{D}_{1}$ and $\mathrm{D}_{2}$.

A typical example of the results obtained at $\mathrm{R}=0.10$ and $\mathrm{R}=0.70$ is given in Figure $6 \mathrm{a}$ and $6 \mathrm{~b}$.

At $\mathrm{R}=0.10$, the percentage of striations reaches a top value for $\mathrm{K}_{\text {max }}$ values ranging from 12 to $28 \mathrm{MPa} \sqrt{m}$ i.e from $\mathrm{T}_{1}$ to $\mathrm{T}_{3}$.

At $R=0.70$, the evolution of the percentage of striations is similar that observed at $\mathrm{R}=0.10$, but quantitative differences exist.

\subsection{Energetic analysis}

The results are analyzed in terms of the energy parameters. The evolution of the crack growth rate with respect to the energy dissipated per cycle $\mathrm{Q}$ for different $\mathrm{R}$ ratios is presented in Figure 7. 


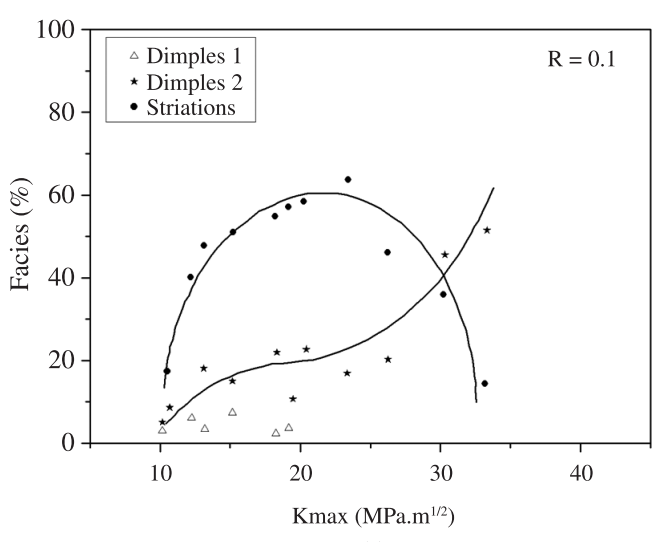

(a)

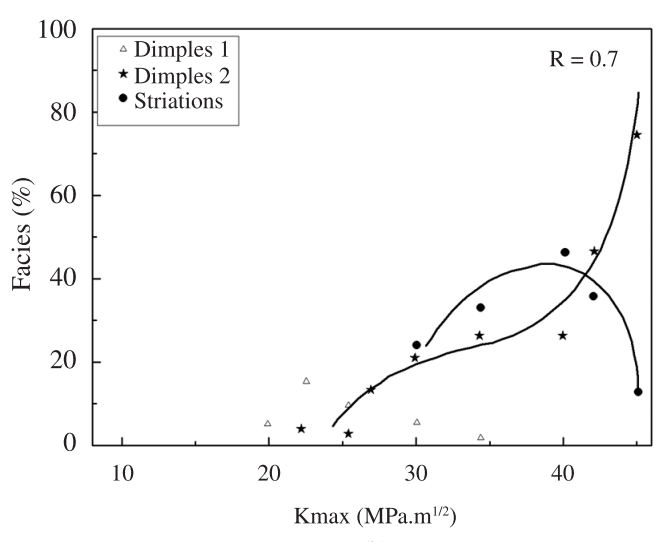

(b)

Figure 6. a) Evolution of significant fractographic features at $R=0.10$; b) Evolution of significant fractographic features at $R=0.70$.

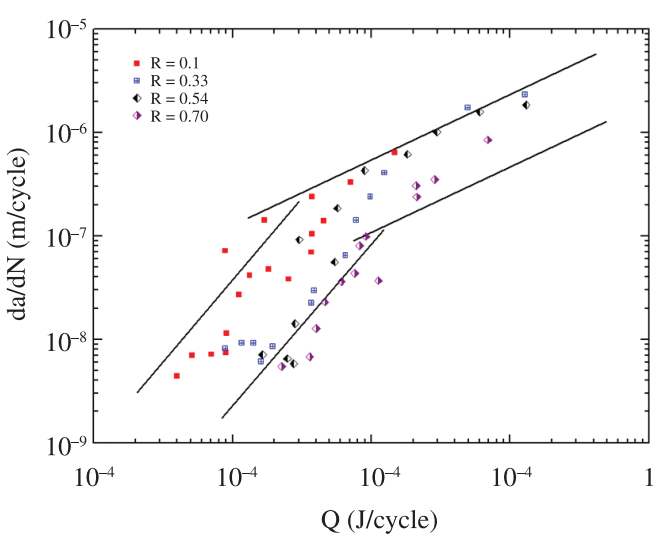

Figure 7. Evolution of the crack growth rate da/dN with respect to energy dissipated per cycle Q.

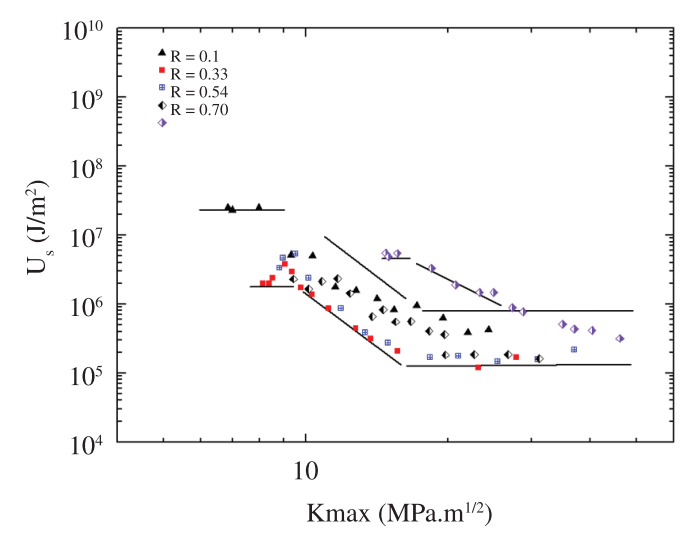

Figure 8. Evolution of the specific energy $U$ with respect to the stress intensity factor $\mathrm{K}_{\max }$.

In this figure, we show the existence of two distinct stages.

At high growth rates values, the relationship between $\mathrm{da} / \mathrm{dN}$ and $\mathrm{Q}$ is linearly and can be expressed as follow (Equation 3):

$\frac{d a}{d N}=A Q$

with A above $1,810^{-4}$
For lower growth rates values, the relationship between $\mathrm{da} / \mathrm{dN}$ and $\mathrm{Q}$ can represent by a power law of the type (Equation 4):

$\frac{d a}{d N}=B Q^{n}$

with

$$
\mathrm{B}=2,2210^{-5}
$$

$\mathrm{n}=3,80$

The relationship between the specific energy $U_{S}$ and $\mathrm{K}_{\max }$ is shown in Figure 8. In this figure, it can be seen that the specific energy $U_{S}$ reaches a minimum level called $U_{c r}$ at about $2,17 \times 10^{5} \mathrm{~J} \cdot \mathrm{m}^{-2}$ when the stress intensity factor reaches a critical value $\mathrm{K}_{\max }=17 \mathrm{MPa} \sqrt{m}$, value comparable to the value of transition $T_{2}$ observed in the curves of propagation (see Figures $4 \mathrm{a}$ and $4 \mathrm{~b}$ ). The fratographic analysis ${ }^{20}$ shows that this change behavior can be associated to step by step mechanism at low growth the crack growth mechanism was characterized by striation formation during for each cycle where the specific energy was constant $t^{21}$.

\section{Conclusion}

Fractographic observations of the fatigue fracture surfaces in the case of high strength aluminum alloy 2024-T351 and their quantitative analysis completed by an energetic parameters analysis lead to the following conclusions:

- The evolution of the typical fractographic features has been correlated to the different propagation regimes which are separated by characteristic transitions. Moreover, the influence of the load ratio $\mathrm{R}$ and the maximum stress intensity factor $\mathrm{K}_{\max }$ is taken into account by the analysis method.

- Most aspects of crack growth mechanism can be explained by the energetic analysis.

The behavior for the material was attributed a crack advances step by step mechanism for lower growth rates and at high growth rates, the crack growth mechanism was characterized by striation formation during for each cycle where the specific energy was constant 


\section{References}

1. Paris PC and Erdogan F. A critical analysis of crack propagation laws. Journal of Basic Engineering. 1963; 85:528-534. http:// dx.doi.org/10.1115/1.3656900

2. Yoder GR, Cooley LA and Crooker TW. On microstructural control of near-threshold fatigue crack growth. Scripta Metallurgica. 1982; 16:1021-1025. http://dx.doi. org/10.1016/0036-9748(82)90448-3

3. Wanhill RJH. Low stress intensity fatigue crack growth in 2024-T3 and T351. Engineering Fracture Mechanics. 1988; 30(2):233260. http://dx.doi.org/10.1016/0013-7944(88)90227-5

4. Grinberg NM. Stage II fatigue crack growth. International Journal of Fatigue. 1984; 6(4):229-242. http://dx.doi. org/10.1016/0142-1123(84)90054-9

5. Klesnil $M$ and Lukas P. Effect of stress cycle asymmetry on fatigue crack growth. Materials Science and Engineering. 1972; 9:231-239. http://dx.doi. org/10.1016/0025-5416(72)90038-9

6. Pelloux RMN. Mechanism of formation of ductile fatigue striations. Transactions of the American Society of Metals Quarterly. 1969; 62:281.

7. Laird C. The influence of metallurgical structure on the mechanisms of fatigue crack propagation. ASTM STP. 1967; 415:131-168.

8. Nix KJ and Flower HM. To use of Electron Optical techniques in the study of fatigue in High strength aluminum alloy 7090. In: Sherraft F and Sturgeon JB. Materials, Experimentation and Design in Fatigue. Surrey: Westbury House Pub; 1979. p. 85.

9. Elber W. The significance of crack closure. ASTM STP. 1971; 486:230-242.

10. Forman RG, Kearney VE and Engle RM. Numerical analysis of crack propagation in cyclic-loaded structures. Journal of Basic Engineering. 1967; 89:459-464. http://dx.doi. org/10.1115/1.3609637

11. Ranganathan N. Contribution au développement d'une approche énergétique à la propagation d'une fissure de fatigue. [Thesis]. Poitiers: University of Poitiers; 1985.
12. Weertman J. Theory of fatigue crack growth based on a BCS crack theory with work hardening. International Journal of Fracture. 1973; 9(2):125-131. http://dx.doi.org/10.1007/ BF00041854

13. Kikukawa M, Jono M and Hora H. Fatigue crack propagation and closure behavior under plane strain condition. International Journal of Fracture. 1977; 13:699-701. http://dx.doi. org/10.1007/BF00017303

14. Ranganathan N, Benguediab M, Henaff G and Adiwijajanto F. Quantitative fracture surface analysis of fatigue crack propagation under variable loading. In: Masters JE, editor. Fractography of Modern Engineering Materials. ASTM STP 1203; 1993. p. 71-94.

15. Underwood EE and Starke Junior EA. Quantitative stereological methods for analyzing important microstructural features in fatigue of metals and alloys. ASTM STP 675; 1979. p. 633-682.

16. Herztberg RW and Mills WJ. Character of fatigue fracture surface micromorphology in ultra low growth rate regime. ASTM STP 600; 1976, p. 220-34.

17. Bates RC and Clark WG. Fractography and fracture mechanics. Transactions of American. Society for Metals. 1969; 62:380-388.

18. American Society for Testing and Materials - ASTM. E 647-96: Standard test method for measurement of fatigue crack growth rates. ASTM; 1999. Annual Book of ASTM Standards. v. 03.01.

19. Benguediab M. Etude de la propagation des fissures de fatigue sous spectres de chargement réduits. [Thesis]. Poitiers: University of Poitiers; 1989.

20. Ranganathan N, Bouchet B and Petit J. Fractography aspects of the effects of environment on the fatigue crack propagation mechanism in a high strength aluminum alloy. ASTM STP 948; 1987. p. 424-446.

21. Ranganathan N. Analysis of fatigue crack growth in terms crack closure and energy. ASTM STP 1343; 1999, p. 14-38. 